\title{
EL IMPACTO DE LOS MEDIOS SOCIALES \\ EN LA ESTRUCTURA DEL SISTEMA DE DISTRIBUCIÓN TURÍSTICO: ANÁLISIS Y CLASIFICACIÓN DE LOS NUEVOS PROVEEDORES DE SERVICIOS TURÍSTICOS EN EL ENTORNO ONLINE
}

\author{
José Ramón Sarmiento Guede \\ Universidad Internacional de la Rioja. \\ Logroño. España
}

\section{RESUMEN}

Las últimas décadas se han caracterizado por el auge de las TIC (Tecnologías de Información y Comunicación) y por el desarrollo de los negocios electrónicos (el llamado e-business). Esto afectó directamente a la industria turística española y, en particular, a la estructura de la distribución de servicios turísticos. Con Internet, se han eliminado las barreras (intermediarios) que separaban la oferta de la demanda y se ha originado un nuevo mapa de distribución de servicios turísticos. Desde la revisión de la literatura, así como de un análisis cualitativo y cuantitativo, esta investigación pretende determinar esa nueva clasificación en un entorno «online» y ver qué uso hacen de él los usuarios.

Palabras clave: Sistemas de Distribución de Turismo; Tecnologías de la Información y Comunicación (TIC); Marketing de Relaciones; Contenido Generado por los Usuarios (CGU); Medios Sociales.

Recibido: 9 de marzo de 2015

Devuelto para su revisión: 6 de septiembre de 2015

Aceptado: 20 de noviembre de 2015

Facultad de Ciencias Jurídicas, Sociales y Humanidades. Universidad Internacional de la Rioja. Apartado 26002 LOGROÑO (España).E-mail: joseramon.sarmiento@unir.net 


\title{
The Social Media impact on the structure of tourism distribution system: analysis and classification of new tourist services providers in the environment «online»
}

\begin{abstract}
The last decades have been marked by the rise of ICT (Information and Communication Technologies) and the development of electronic business (e-business called). The Spanish tourism industry and in particular the structure of tourism distribution system was directly affected by it. Internet has removed barriers (intermediaries) separating offer and demand. So, it has led a new distribution map of tourist services. From the literature review and a qualitative and quantitative analysis, this research aims to determine the new classification in an online environment and see what use is made from it for the users.
\end{abstract}

Keywords: Tourism Distribution System; Information and Communication Technologies (ICT); Relationship Marketing; User Generated Content (UGC); Social Media.

\section{INTRODUCCIÓN}

Las TIC (Tecnologías de la Información y Comunicación) ${ }^{1}$ y las relaciones (Marketing de Relaciones) son la estructura fundamental sobre la que descansa la industria turística española (Alfaro et al., 2004). La información es como el «alma» del turismo y, por lo tanto, la tecnología resulta fundamental para la capacidad de funcionamiento de la industria (Copper et al., 2005). Además, Internet es mejor que otros medios convencionales a la hora de facilitar la construcción de relaciones (Wang et al., 2003); es algo esencial para dar un buen servicio, desarrollar una relación de calidad y poder fidelizar a los usuarios. Si ha habido dos fenómenos que, en los últimos años, han revolucionado las prácticas, las funciones, los usos y las investigaciones en la industria turística española, esos han sido, por un lado, el Marketing de Relaciones y, por otro, la aparición, la utilización y el desarrollo de las TIC.

La incidencia de las TIC y del Marketing de Relaciones en la distribución del servicio turístico ha suscitado el interés de la investigación desde finales de los años noventa (Poon, 1993; Bloch, 1996; Sheldon, 1997; Copper et al., 2005; Buhalis y Law, 2008; Berné et al., 2012; Sarmiento, 2014). Las TIC han potenciado las relaciones de intercambio, han permitido personalizar los servicios y han otorgado mayor poder a los proveedores. La nueva estructura de la distribución que se está generando gracias a las TIC puede hacer peligrar la intermediación tradicional (Saloner y Spence, 2002; Berne et al., 2012), lo que llevaría a un nuevo mapa en la distribución turística en el contexto «online» (Poon, 1993; Buhalis, 1998; Rodríguez, 2002; Sellers y Azorín, 2001; Buhalis y Law, 2008; Berné et al., 2012). En consecuencia, una investigación como la realizada está más que justificada. Para este trabajo de investigación de los sistemas de distribución turísticos en el entorno «online» nos hemos marcado dos objetivos:

\footnotetext{
1 En adelante las TIC.
} 
1. Identificar desde un enfoque cualitativo la nueva clasificación surgida.

2. Analizar desde un enfoque cuantitativo el uso que hacen los usuarios de ella.

Para alcanzar los dos objetivos propuestos, empezaremos por la presentación del marco teórico que circunscribe este trabajo de investigación, esto es, las TIC, el sistema de distribución de servicios turísticos y los Medios Sociales. En este sentido, se hace indispensable realizar una revisión bibliográfica en la que se analicen las implicaciones que tienen las TIC en la industria turística y en la nueva clasificación del sistema de distribución de servicios turísticos «online». Además, resaltaremos la importancia de los Medios Sociales en el nuevo mapa. Hecho lo cual, detallaremos la metodología desde un enfoque cualitativo y cuantitativo para presentar en el apartado siguiente los resultados de dicha clasificación y de su uso. Teniendo en cuenta los resultados, llegaremos a unas conclusiones que servirán para explicar qué papel desempeñan los Medios Sociales en la clasificación de los sistemas de distribución turística. No olvidamos que es un campo de estudio novedoso y de cierta relevancia tanto desde un punto de vista académico como profesional, ya que Internet es un canal directo e ideal para crear, desarrollar y mantener relaciones con los usuarios.

\section{MARCO TEÓRICO}

La bibliografía especializada reconoce que las TIC están modificando el papel de los sistemas de distribución en las organizaciones, lo cual exige una adaptación continua a este entorno «online». Dicho esfuerzo, provoca a su vez una nueva clasificación en el entramado turístico y la necesidad de sistemas más dinámicos y competitivos (Frew, 2000; Leung y Law, 2007; Buhalis y Law, 2008; Berné et al., 2012). Así pues, dividiremos y analizaremos el marco teórico en tres apartados:

1. La influencia de las TIC en la industria turística.

2. El sistema de distribución de servicios turísticos.

3. Los nuevos intermediarios de la industria turística «online».

\subsection{La influencia de las TIC en la industria turística}

Las TIC suelen definirse como «toda la gama de instrumentos electrónicos que facilitan la gestión operativa y estratégica de las organizaciones capacitándolas para gestionar su información, sus funciones y sus procesos y, además, para comunicarse de forma interactiva con todas las partes interesadas a fin de cumplir su misión y sus objetivos» (Buhalis, 2003, en Copper et al., 2005:831). Hasta el momento, se pueden identificar cuatro etapas principales en el desarrollo de las TIC (Copper et al., 2005:830):

1. «Procesado de datos». El principal objetivo de esta etapa situada en la década de los setenta era mejorar la eficiencia operativa a través de la automatización de los procesos basados en la información. 
2. «Sistema de información de gestión (SIG)». Esta etapa empezó en la década de los setenta y su principal objetivo consistía en aumentar el nivel de eficacia cubriendo las necesidades de las organizaciones.

3. «Sistema de información estratégica (SIE)». Surgió a principios de los ochenta. Su objetivo era mejorar los niveles de competitividad cambiando la naturaleza de los negocios o la forma de llevar a cabo las transacciones.

4. «La red de redes». La implantación de Internet a principios de los noventa dio paso a una nueva etapa de mayor relevancia, durante la cual proliferó el uso de redes como Internet, Intranet y Extranet, lo cual posibilitó una comunicación eficiente, multinivel e interactiva. En consecuencia, acarreó cambios en el mercado global, sobre todo, en aspectos de localización y tamaño de la organización.

Las TIC facilitan a las organizaciones turísticas el desarrollo de sus procesos y la adaptación de sus prácticas de gestión con vistas a aprovechar los instrumentos y los mecanismos digitales emergentes y alcanzar las metas siguientes (Copper et al., 2005:834):

1. Aumentar su eficiencia interna, gestionar mejor su capacidad y sus ingresos (Buhalis y Law, 2008; Berné et al., 2012).

2. Interactuar de forma efectiva con los usuarios y personalizar el servicio (Poon, 1993; Buhalis, 2004; Berné et al., 2012).

3. Revolucionar la intermediación turística y aumentar el número de puntos de venta (Berné et al., 2012).

4. Facilitar a los usuarios herramientas que permitan comunicarse entre ellos (Berné et al., 2012; Sarmiento, 2014).

5. Fomentar una cooperación eficiente entre los socios dentro del sistema de valores (Berné et al., 2012).

6. Ampliar el ámbito operativo y geográfico ofreciendo herramientas estratégicas para la expansión global (Porter, 1990).

Uno de los aspectos más importantes es controlar la gestión del canal distribución, ya que sus miembros son, por definición, dependientes unos de los otros (Coughlan et al., 2001). Como muy bien señala Berné et al. (2012:120), «el poder está relacionado con el control. Un agente con poder puede ejercerlo en el canal que controla. Si se examina la cadena de valor de la industria turística, se observa que la actividad relacionada con la manipulación y la distribución de información es el corazón de su riqueza y de su progreso» (Poon, 1993). En el canal de distribución de los servicios turísticos, el poder ha cambiado drásticamente en los últimos años gracias a las TIC. En la actualidad, tiene más importancia el «marketspace» que el «marketplace» (Gummesson, 2002), ya que en el contexto «online»y, en particular, con la llegada de los Medios Sociales, los usuarios (clientes finales) son quienes tienen el poder en los canales de distribución de servicios turísticos y la única alternativa para las organizaciones es ofrecer valor y co-crear valor (Vargo y Lusch, 2004). 


\subsection{El sistema de distribución de servicios turísticos}

Berné et al. afirman que, desde los años ochenta, las TIC han transformado el mercado turístico de manera global. El posicionamiento de las centrales de reservas (CRS) en los setenta, los sistemas globales de distribución (GDS) a finales de los ochenta y el desarrollo de Internet a finales de los noventa han provocado una transformación radical en la operativa y en las estrategias de la industria turística (Emmer et al., 1993; O'Connor, 2003; Buhalis, 2003; Berné et al., 2012). Uno de los aspectos más destacables ya mencionado es la fuerte dependencia que los proveedores tienen de los intermediarios turísticos, ya que estos participan al principio y al final del servicio turístico (Berné et al., 2011). A continuación, analizaremos los cambios más significativos que han provocado las TIC en el sistema de distribución. Copper et al., (2005) entienden que, en todas las industrias, la tarea de los intermediarios consiste en transformar unos servicios que no son del agrado de los consumidores, dándoles otra forma que sí sea de su gusto. En la siguiente figura (ver figura 1), se puede observar el diagrama de la estructura de los canales de distribución, que podemos dividir en dos tipos (Berné et al., 2011:28):

1. «Canales directos», que son un acceso más rápido y menos costoso al servicio turístico final debido a que no participan los intermediarios.

2. «Canales Indirectos», en los que los intermediarios mayoristas canalizan la mayor parte de las contrataciones desde la promoción y la negociación del servicio, lo que encarece el servicio turístico.

En el sector turístico, en la era previa al desarrollo de Internet, la opción más factible era el uso del canal indirecto, puesto que los intermediarios (CRS, GDS, AAVV y TTOO) facilitaban el proceso de producción y distribución turística (Sheldon, 1997; O'Connor, 2003; Copper et al., 2005; Berné et al., 2011; Berné et al., 2012).

\section{Figura 1}

\section{ESTRUCTURA TRADICIONAL DEL SISTEMA DE DISTRIBUCIÓN TURÍSTICA}

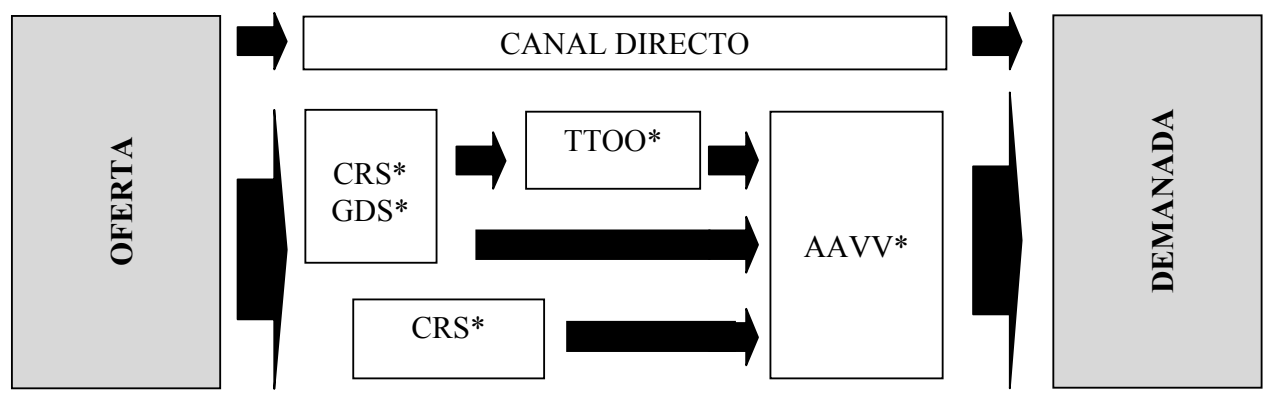

* GDS: Global Distribution Systems; CRS: Centrales de Reservas; TTOO: tour-operadores; AAVV: Agencias de viaje.

Fuente: Sancho (1998:149). 
En esta estructura del sistema planteada por Sancho (1998), los intermediarios y usuarios dependen en gran medida de la información recibida por los proveedores, clave en el proceso de decisión de compra del usuario (cliente final) (Berné et al., 2011). Además, según Buhalis y Law, (2008), este esquema está sujeto a constantes modificaciones como resultado de la existencia de las TIC.

A partir de los años noventa, la estructura del sistema de distribución (Berné et al., 2011) y la manera de hacer negocios (Kale y McIntyre, 1991; Tiwana, 1998) cambian drásticamente con la llegada de Internet. Entre los cambios más importantes, podemos señalar los siguientes: (a) surgen nuevos medios de comercialización a través de los cuales se llega de una forma más fácil a los usuarios (Gunasekaran et al., 2002); (b) se modifica la intensidad de las relaciones entre los miembros del canal (Berné et al., 2012); (c) las empresas de la industria turística planifican, controlan, operan e integran las TIC en sus actividades (Kasavana y Cahill, 1992), lo que produce un gran volumen de actividad y de calidad (Christian, 2001); (d) se incrementa la competitividad y las posibilidades de rendimiento del negocio turístico (Berné et al., 2011), puesto que las TIC proporcionan herramientas eficaces a los proveedores para desarrollar, dirigir y distribuir sus ofertas por todo el mundo (Buhalis, 1998).

Internet está considerada como un canal esencial para la distribución, pues permite a los proveedores turísticos una comunicación directa con sus usuarios en las mismas condiciones que los intermediarios (Berné et al., 2011). Ante esta situación, los intermediarios reaccionan y empiezan a ofrecer a los usuarios un servicio turístico final más personalizado. Con todo ello, como muy bien explican Berné et al. (2011), se empieza a desarrollar una rivalidad entre canales directos e indirectos.

Sellers y Azorín (2001) amplían la versión tradicional del sistema de distribución turístico al considerar Internet como lo que justifica la presencia del canal directo (ver figura 2). En su modelo, indican que «el canal de distribución turístico se puede definir como la estructura formada por el conjunto de organizaciones que tiene como objetivo facilitar y poner a disposición del mercado los productos turísticos ofertados por los distintos productores. Tradicionalmente, la distribución en el sector turístico ha estado en manos de las AA.VV. mayoristas, minoristas y mayoristas/minoristas que, junto con las centrales de reserva y sistemas globales de distribución, realizan las funciones de intermediación dentro del sector» (Sellers y Azorín, 2001:20). Con la llegada de Internet, los usuarios pueden utilizar los canales directos, indirectos (a través de intermediarios) o una combinación de ambos. La decisión sobre el tipo de canal a utilizar dependerá básicamente de las ventajas e inconvenientes que a través de Internet la distribución directa proporciona a los proveedores de servicios turísticos, las agencias de viajes y los clientes (Sellers y Azorín, 2001).

Ahora bien, en los últimos años hemos visto cómo otro fenómeno denominado Medios Sociales, o aplicaciones web 2.0, está modificando de una manera considerable la estructura del sistema de distribución. Actualmente, proveedores, distribuidores y usuarios se benefician de las aplicaciones tecnológicas. La cuestión es cómo se transforma la estructura tradicional del sistema de distribución turístico con el creciente uso de los Medios Sociales. Ante este contexto, cabe plantearse qué puede ocurrir si desaparecen los intermediarios y cómo evolucionará el canal de distribución turístico (Sellers y Azorin, 2001; Berné et al., 2011; Berné et al., 2012). Y, como muy bien apuntaban Sellers y Azorin 


\section{Figura 2 \\ EL CANAL DE DISTRIBUCIÓN TURÍSTICA}

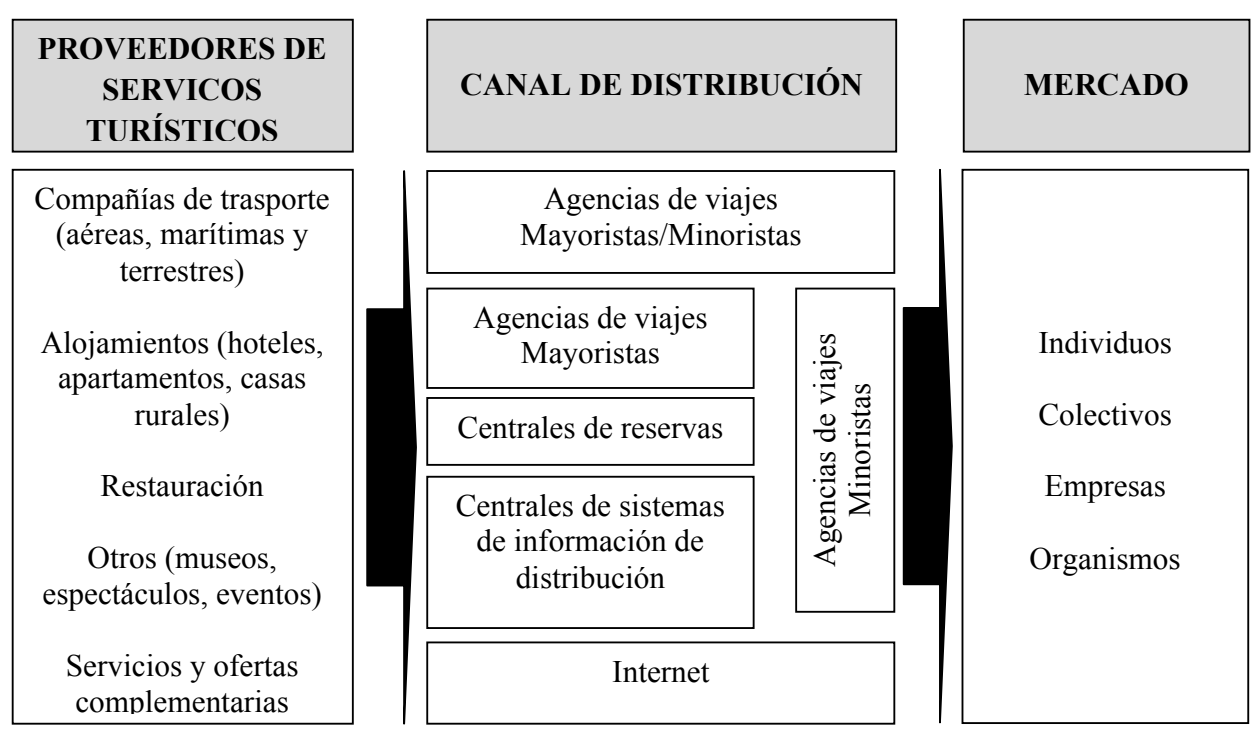

Fuente: Sellers y Azorin (2001:19).

(2001), la clave siempre se encontrará en los usuarios (consumidores), en considerar sus usos, sus hábitos y costumbres en cuanto atañen a la utilización de los diferentes canales de distribución.

Buhalis (2003:271) sugiere que, «dado que Internet permite, por un lado, a los agentes principales y a los destinos, promocionar sus productos en línea y, por otro, a los consumidores, preparar y comprar sus propios itinerarios sin ayuda externa, da la impresión de que el futuro de las agencias de viaje es bastante incierto». Si este hecho se produjera, estaríamos hablando de la desintermediación de la estructura del sistema de distribución turístico (Buhalis, 1998; Doherty, Ellis-Chadwick y Hart, 1999; Sellers y Azorin, 2001; Buhalis, 2003; Berné et al., 2011; Berné et al., 2012). La «Red de redes» ha propiciado que todas las organizaciones turísticas traten de desintermediar a los demás intermediarios (Buhalis y Law, 2008; Vallespín y Molinillo, 2014). Por ello, nuestro trabajo de investigación se centra en una nueva clasificación de la estructura del sistema de distribución en el «marketspace» con la irrupción de las TIC y, en particular, con la de los Medios Sociales.

\subsection{Los nuevos intermediarios de la industria turística «online»}

La llegada de los Medios Sociales al sector de los viajes ha provocado que casi el $40,2 \%$ de los usuarios afirme que en el futuro renunciará a organizar un viaje en el «marketplace» para poder hacerlo solamente a través del «marketspace» (Novak y Schwabe, 2009; Vallespín y Molinillo, 2014). Ante este contexto, el uso de los Medios Sociales 
han favorecido la aparición y expansión de nuevos intermediarios en el entorno «online», resultando más atractivos que los canales tradicionales, ya que el usuario co-crea valor junto con la organización (Lusch y Vargo, 2006). Este tipo de usuarios que se sienten atraídos por los Medios Sociales y que quieren crear su propio servicio son conocidos como «prosumidores». Dicho concepto fue introducido por primera vez por Toffler (1984), quien afirma que las funciones de los productores y los consumidores se mezclan hasta tal punto que los individuos están involucrados en el diseño y fabricación de productos o servicios. En este contexto, el usuario ya no es un receptor pasivo, sino que busca su participación activa. Según Tapscott (2009), los «prosumidores» de hoy en día están utilizando activamente los Medios Sociales para participar en el aumento de los niveles de colaboración e interactividad con las organizaciones.

Los términos Medios Sociales y web 2.0 aparecen a menudo como intercambiables en la literatura específica utilizada; sin embargo, algunos investigadores asocian el término web 2.0, principalmente, con las aplicaciones en línea de las que dispone un sitio web; otros investigadores asocian los Medios Sociales con los aspectos que pueden desarrollarse con las aplicaciones de la web 2.0, es decir, participación, conversación, interactividad, comunidad, compartir, generar, etc. (Constantinides y Fountain, 2007). Web $2.0^{2}$ es un término acuñado por Tim O’Reilly (2005) y sus características principales son las siguientes: (a) la propia Web se convierte en la plataforma y se basa en el uso de los estándares abiertos, descentralizados y protocolos de Internet (XML, HTML, SOAP AJAX); (b) la Web se utiliza para aprovechar la inteligencia colectiva de sus usuarios, también conocida como la sabiduría de las multitudes (Surowiecki, 2004); (c) los datos, el contexto y el contenido representan el valor en lugar del «hardware o software»; (d) tiene que ser un modelo de negocio abierto y que pueda ser compartido; y (e) la experiencia del usuario ha de ser compartida y facilitada gracias a las tecnologías de la animación, visualización y la interactividad (O’Reilly, 2005). Kaplan y Haenlein (2009) coinciden con Constantinides y Fountain (2008) en afirmar que la web 2.0 son plataformas en línea en donde los Medios Sociales se han desarrollado. Los Medios Sociales pueden definirse como «un grupo de aplicaciones basadas en Internet que se desarrollan sobre los fundamentos ideológicos y tecnológicos de la web 2.0, y que permiten la creación y el intercambio de contenidos generados por el usuario» (Kaplan y Haenlein, 2009:61). En el mismo sentido, Boyd y Ellison (2008:211) definen los Medios Sociales como «servicios basados en la Web que permite a los individuos: (a) construir un perfil público o semi-público dentro de un sistema delimitado; (b) articular una lista de otros usuarios con los que comparten una conexión; y (c) ver la lista de conexiones y las hechas por otros dentro del sistema. La naturaleza y la nomenclatura de estas conexiones pueden variar de un sitio a otro».

En la actualidad, los usuarios que pretenden organizar sus viajes desde un contexto «online» tienen ante ellos una enorme variedad de sitios web con aplicaciones web 2.0 (Medios Sociales). Entre los nuevos intermediarios, Buhalis y Law (2008) identifican los sistemas de reservas, agencias de viaje «online», buscadores, metabuscadores, sistemas de gestión de destinos, redes sociales y comparadores de precios (Vallespín y Molinillo,

2 En la literatura al uso siempre ha existido una falta de claridad en torno a la diferencia entre la web 2.0 y los Medios Sociales, ya que siempre se han utilizado los dos términos para describir lo mismo. En este trabajo se utilizará el término Medios Sociales. 
2014). Vallespín y Molinillo (2014) resaltan que las ventajas para el usuario de estos nuevos intermediarios son su bajo coste, la facilidad a la hora de comparar productos, el acceso a información personalizada, la interactividad y la posibilidad de acceso a cualquier hora del día (Roselló y Riera, 2012). Según Rensmann (2012), hasta ahora pocos trabajos de investigación se han centrado en establecer una clasificación de los diferentes modelos de negocio electrónicos existentes en el sector turístico, lo que justifica que nuestro trabajo tenga por objeto presentar una clasificación de los nuevos intermediarios «online» del sistema de distribución turístico (Vallespín y Molinillo, 2014).

\section{METODOLOGÍA}

La metodología con que se realiza el presente trabajo de investigación se ha estructurado en dos apartados: un primero (1) en el que se utilizan técnicas de carácter cualitativo, de la que se ha obtenido la clasificación de los nuevos intermediarios, y otro segundo (2), que se sirve de ella para abordar la investigación cuantitativa.

En el apartado cualitativo, se realizaron dos reuniones de grupo (focus group), con el objetivo de conocer la clasificación más idónea desde su punto de vista de expertos en el sector turístico. La muestra estaba formada por 30 personas (19 hombres y 11 mujeres), de diferentes nacionalidades, con edades comprendidas entre los 25 y 65 años. Siguiendo a Landeta (1999) y Vallespín y Molinillo (2014), consideramos experto a todo aquel individuo que pueda aportar información, objetiva o subjetiva, válida para la realización de la previsión. Los expertos seleccionados son los siguientes (Vallespín y Molinillo, 2014:17):

a) Académicos cuya línea de investigación está relacionada con los Medios Sociales y el turismo, y que fueron identificados por su contribución a la bibliografía.

b) Profesionales del ámbito turístico que representan a la mayoría de los sectores: directores de empresas de servicios turísticos (hoteles y empresas de transporte fundamentalmente), directores de empresas intermediarias (AAVV y TTOO) y directores de empresas de soluciones tecnológicas cuyos clientes son las empresas turísticas.

c) Máximos responsables de la administración cuyo cargo actual les permite tener una visión amplia sobre qué es lo que está ocurriendo en el sector y qué ocurrirá en un futuro próximo en el canal de distribución.

En los dos grupos se utilizó la técnica de la entrevista de forma no estructurada y natural, en la que un moderador (en este caso el investigador) guía la discusión con el propósito de obtener información al escuchar a los grupos de personas del mercado meta para llegar al principal objetivo de esta primera fase. Los datos del estudio cualitativo fueron analizados con el programa de Atlas.ti 7. Los resultados fueron los siguientes (ver cuadro 1):

1. Confirmar algunos tipos de intermediarios obtenidos a partir de la revisión bibliográfica, como pueden ser las Agencias de viajes (Vallespín y Molinillo, 2014), Tour-operadores (Vallespín y Molinillo, 2014), Sistemas globales de distribución (Vallespín y Molinillo, 2014), Centrales de reserva (Vallespín y Molinillo, 2014), AAVV virtuales (OTA) (Buhalis y Law, 2008; Vallespín y Molinillo, 2014; Sarmiento, 2014). 
2. Identificar nuevos intermediarios o confirmarlos como pueden ser sitios web de destinos (Buhalis y Law, 2008; Vallespín y Molinillo, 2014; Sarmiento 2014), sitios web de opinión (Buhalis y Law, 2008; Sarmiento, 2014) y los motores de búsqueda (Buhalis y Law, 2008; Vallespín y Molinillo, 2014; Sarmiento 2014).

3. Excluir, modificar o agrupar algunos intermediarios que no encajaban dentro del sistema de distribución de servicios turístico «online».

\section{Cuadro 1 \\ LOS NUEVOS PROVEEDORES E INTERMEDIADORES DEL SISTEMA DE DISTRIBUCIÓN DE SERVICIOS TURÍSTICOS «ONLINE»}

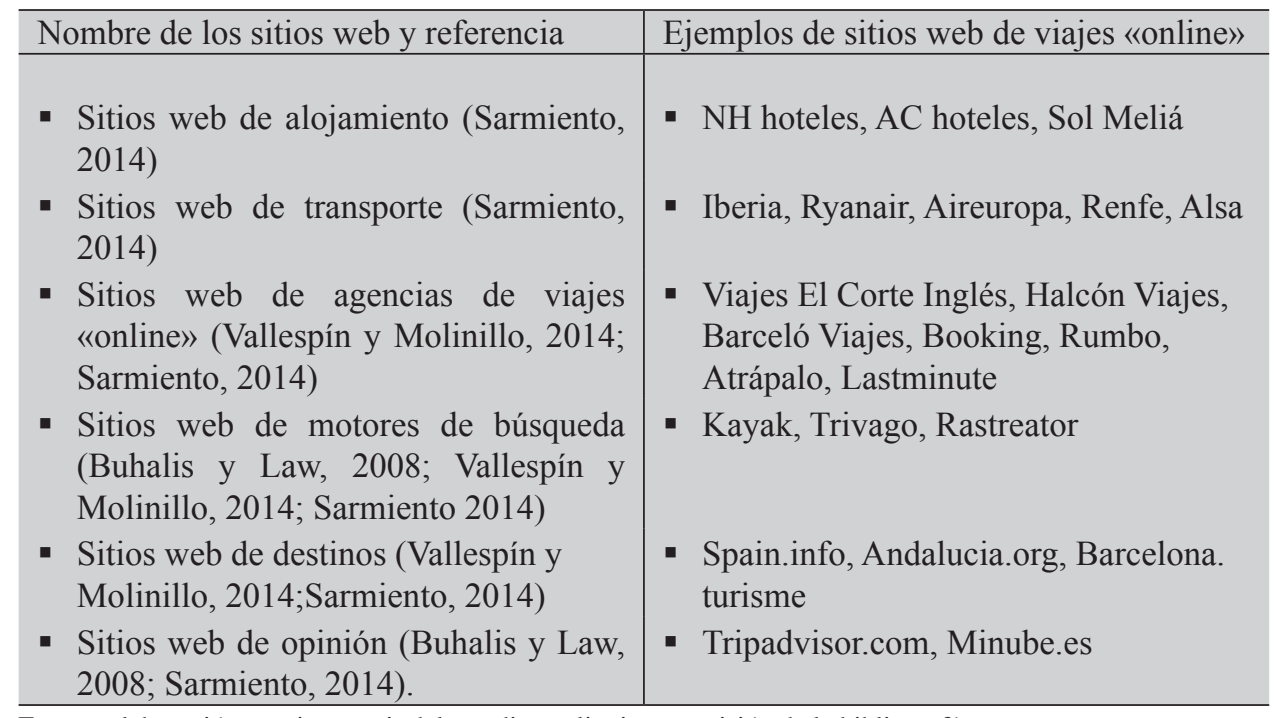

Fuente: elaboración propia a partir del estudio cualitativo y revisión de la bibliografía.

Para este trabajo de investigación, las agencias de viajes, los tour-operadores, los sistemas globales de distribución y las centrales de reservas se agruparon en un grupo denominado agencias de viajes «online», ya que se entendía que todos esos sitios web son los necesarios para desarrollar o elaborar un servicio turístico y presentárselo al cliente sin que éste tenga que molestarse en navegar por distintos sitios web de viajes. Los buscadores (ej. Google), aunque son una herramienta muy importante, fueron eliminados de la nueva clasificación, pues entendemos que son sitios web muy generalistas y nosotros intentamos realizar una clasificación de los sitios web de viajes (intermediarios y proveedores de servicios turísticos).

Otro aspecto importante de la investigación cualitativa es que, en el contexto «online», el papel de intermediarios o proveedores se intercambia con bastante facilidad, es decir, en algunos casos los sitios web hacen de intermediarios y en otros casos hacen de proveedores. Los proveedores tradicionales del sistema siempre han sido los proveedores de alojamiento, trasporte, restauración u otros servicios complementarios (museos, espectá- 
culos, musicales, etc.). El problema radica en que, con la llegada de los Medios Sociales, se ha desarrollado otro tipo de proveedores de contenido generado por los usuarios (CGU), donde el usuario dispone información, imágenes o vídeos sobre los proveedores tradicionales. En este caso, los proveedores tradicionales se sirven de este contenido, es decir, hacen de intermediarios para hacerles llegar a sus posibles clientes un contenido más fiable. Todos estos resultados se utilizaron para su posterior estudio en el análisis cuantitativo.

\section{Figura 3 \\ EL NUEVO SISTEMA DE DISTRIBUCIÓN DE SERVICIOS TURÍSTICOS EN EL ENTORNO «ONLINE»}

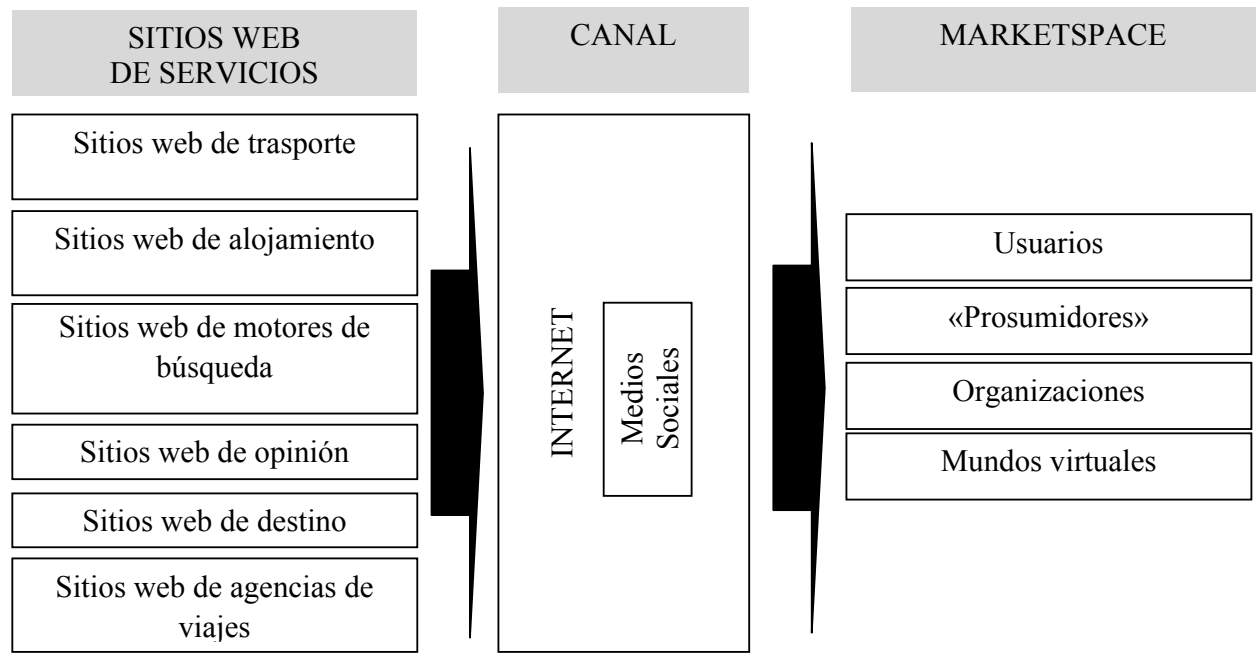

Fuente: elaboración propia a partir del estudio cualitativo y revisión de la bibliografía

En el apartado cuantitativo, se escogió a jóvenes universitarios de la Comunidad de Madrid con el objetivo de conocer el nivel de uso de los nuevos sitios web de servicios turísticos. El principal motivo de seleccionar esta población radicó en que necesitábamos unos criterios para la unidad de muestra que solo podíamos encontrar en dicha población. La Comunidad de Madrid fue elegida por ser la comunidad en la que más se utilizan los Medios Sociales y los jóvenes universitarios, por ser la población con mayor índice de afinidad, equivalente a 218 en el tramo de edad de 18 a 24 años. En total, la población objeto de estudio fue de 32702 estudiantes de universidades ubicadas en la Comunidad de Madrid. Para la recogida de información se utilizó la técnica de la encuesta personal y el cuestionario como herramienta.

El cuestionario estaba formado por 12 preguntas relativas a los diferentes sitios web de servicios turísticos de la nueva clasificación presentada. Constaba de tres apartados: el primero era una pregunta filtro para dar mayor validez a nuestro trabajo de investigación; el segundo consistía en nueve preguntas relacionadas con el uso de los sitios web de ser- 


\section{Cuadro 2 \\ FICHA TÉCNICA DE LA INVESTIGACIÓN}

\begin{tabular}{l|l}
\hline \multicolumn{2}{c}{ Características de la población y la muestra } \\
\hline Ámbito geográfico & $\begin{array}{l}\text { Comunidad de Madrid } \\
\text { Jóvenes universitarios de la Comunidad } \\
\text { de Madrid }\end{array}$ \\
Mublación & $\begin{array}{l}\text { Bibliotecas de las universidades públicas } \\
\text { y privadas } \\
\text { Jóvenes universitarios de 18 a 24 años }\end{array}$ \\
Unidad de la muestra & Encuesta personal \\
Técnica de recogida de información & $4,27 \%$ \\
Error de la muestra & $95 \%$ \\
Nivel de confianza & 10 minutos \\
Tiempo medio de cumplimentación & Probabilístico estratificado y aleatorio \\
Método de la muestra & simple \\
& 576 encuestas \\
Tamaño de la muestra & Días 20, 21, 22, 23 y 24 de octubre del \\
Período de recogida & 2014. Horario: de 10:00 a 14:00 por la \\
& mañana y de 16:00 a 19:00 por la tarde \\
Tasa de no respuesta & $0,03 \%$ \\
Tasa de negatividad & $4 \%$ \\
Programa de análisis de datos informáticos & IBM/ SPSS V.20 \\
& \\
\hline
\end{tabular}

Fuente: elaboración propia.

vicios turísticos; y el último eran dos preguntas demográficas. El cuestionario se realizó con 576 personas, con un error de muestra del 4,27\% y un nivel de confianza del $95 \%$. Previamente, se comprobó la adecuación del cuestionario a través de un pre-test, basado en un número reducido de personas (30). Para nuestro cuestionario, se utilizaron preguntas estructuradas múltiples, dicotómicas y de escala. Para la medición de preguntas de escala se utilizó la escala de Likert de 5 puntos, donde 1 indicaba que el encuestado estaba muy en desacuerdo y 5, que estaba muy de acuerdo. Con el fin de contrastar la fiabilidad de la misma, se ha calculado el coeficiente de Alfa de Cronbach para todas las preguntas, obteniéndose un valor de 0,790. Para el análisis e interpretación de los resultados, se utilizó el SPSS y técnicas univariantes (distribución de frecuencias, promedios, medidas de dispersión). Para llevar a cabo el trabajo de campo, además de utilizar el cuestionario, se utilizó una ficha técnica de apoyo en la que venía la nueva clasificación del sistema de distribución de servicios turísticos presentada a partir de la investigación cualitativa (ver figura 3). 


\section{ANÁLISIS E INTERPRETACIÓN DE RESULTADOS}

En este apartado, se presentan el análisis y los resultados de los datos obtenidos de las 576 encuestas realizadas a los estudiantes universitarios de la Comunidad de Madrid que usan los sitios web de servicios turísticos (proveedores e intermediadores del sistema de distribución). Los porcentajes ofrecidos en los siguientes cuadros y figuras están calculados en función del tamaño de la muestra de 576 encuestas a través del muestreo probabilístico estratificado y aleatorio simple. Este método ha permitido obtener una muestra que, tanto en tamaño como en forma, es representativa de la sociedad objeto de estudio.

\section{Figura 4 \\ ¿CON QUÉ FRECUENCIA UTILIZA LOS SITIOS WEB DE VIAJES?}

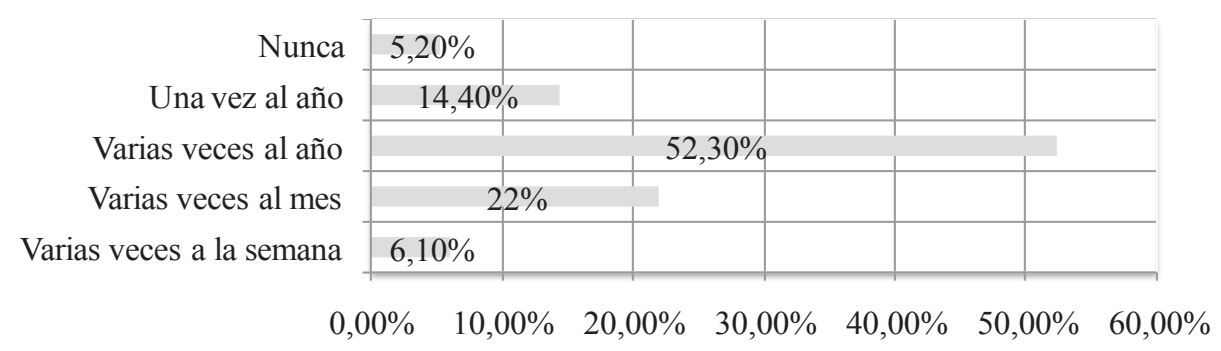

Fuente: elaboración propia.

En la pregunta uno, se interroga al encuestado por la frecuencia de utilización de sitios web de servicios turísticos. Esta primera pregunta la hemos clasificado como «pregunta filtro» con la finalidad de eliminar a las personas que no han utilizado los sitios web de servicios turísticos. Las 576 encuestas repartidas fueron consideradas como válidas, y ninguna como perdida. La media de la utilización de los sitios web de servicios turísticos es del 2,91; lo que indica que la mayoría de los usuarios utiliza entre una y varias veces al año los sitios web de servicios turísticos. La desviación típica del análisis de esta variable se sitúa en el 0,899; lo cual significa que dicha variable es heterogénea al estar compuesta por resultados de distinta naturaleza. En la figura 4, se visualiza que el resultado más significativo: el 52,3\% (301 de los 576 usuarios) de los encuestados utiliza varias veces al año los sitios web de servicios turísticos y el menos significativo: el 5,2\% (30 de los 576 usuarios) de los encuestados nunca ha utilizado un sitio web de servicios turísticos, razón por la que excluimos a estos últimos del resto de preguntas excepto de las socio-demográficas. Por último, señalaremos los demás resultados de esta variable: el 6,1\% (35 de los 576 usuarios) utiliza los sitios web de servicios turísticos semanalmente; el 22\% (127 de los 576 usuarios), mensualmente; y, por último, el 14,4\% (83 de los 576 usuarios) solo los ha utilizado una vez al año. Una vez excluidas las 30 encuestas del total (576 encuestas), basaremos el análisis en las 546 encuestas que tienen relación con los usuarios que han utilizado alguna vez los sitios web de servicios turísticos. 
En la pregunta segunda, se interroga al encuestado para saber si utiliza estos sitios web de servicios turísticos para planificar su viaje. Las encuestas válidas han sido 546 de un total de 546. En la figura 5, podemos visualizar que al 99,60\% (544 de las 546 encuestas válidas) de los usuarios ha utilizado alguna vez los sitios web de servicios turísticos para planificar su viaje, por lo que este resultado es el más significativo. Por el contrario, el 0,4\% (2 de las 546 encuestas válidas) de los usuarios nunca los ha utilizado. La media es de 1,00 y la desviación típica es de 0,060 , lo que prueba que los resultados son muy homogéneos.

\section{Figura 5 \\ ¿HA UTILIZADO ALGUNA VEZ ALGÚN SITIO WEB DE SERVICIOS TURÍSTICOS PARA PLANIFICAR SU VIAJE?}

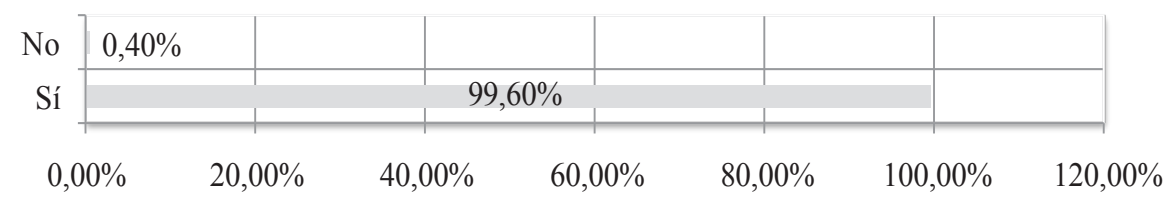

Fuente: elaboración propia.

En la pregunta tercera, se interroga al encuestado para saber si genera contenido en alguno de los sitios web de servicios turísticos, es decir, si comparte información, imágenes o vídeos de sus viajes o experiencias turísticas a través de dispositivos móviles. El número de encuestas válidas ha sido de 545, y solo una ha sido excluida del análisis. Esto se debe, principalmente, a que el encuestado no ha respondido a la pregunta solicitada. En este sentido, conviene recordar que son numerosos los investigadores que asocian la falta de respuesta a diversas causas, entre ellas, al desconocimiento de la información solicitada, al rechazo de las personas a proporcionar información sobre temas sensibles, a la negativa de participar en el trabajo de investigación, así como a causas asociadas a la calidad del marco del muestreo. La media de utilización de dispositivos móviles para generar contenido en los sitios web de servicios turísticos es de 1,74. Este porcentaje indica que la mayoría de los usuarios de sitios web de servicios turísticos no genera contenido sobre sus viajes desde su dispositivo móvil. La desviación típica del análisis de esta variable se sitúa en el 0,436, lo que nos lleva a apreciar una variable más homogénea, puesto que la mayoría de los usuarios coincide en responder negativamente a esta pregunta. La figura 6 ilustra que el 74,4\% (406 de los 545 usuarios) nunca ha utilizado dispositivos móviles para generar contenido de sus viajes en los sitios web de servicios turísticos y que el 25,5\% (139 de los 545 usuarios) sí los ha utilizado para ello.

En las siguientes preguntas, se indica al encuestado que valore los principales motivos por los que utiliza los sitios web de viajes (comprar; dar una opinión; ver imágenes; visionar vídeos; leer comentarios; comparar precios; y buscar información). Las siguientes preguntas son de tipo escala, donde 1 equivale a nada; 2 equivale a alguna vez; 3 equivale a normalmente; 4 equivale a casi siempre, y 5 equivale a siempre. 


\section{Figura 6 \\ ¿ACOSTUMBRA A REALIZAR COMENTARIOS DE SUS VIAJES DESDE UN DISPOSITIVO MÓVIL (SMARTPHONE, TABLETS, ETC.)?}

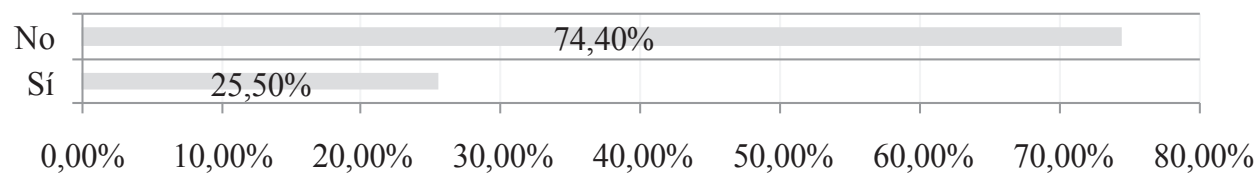

Fuente: elaboración propia.

\section{Figura 7}

\section{CALIFIQUE LOS PRINCIPALES MOTIVOS POR LOS QUE UTILIZA LOS SITIOS WEB DE VIAJES (COMPRAR)}

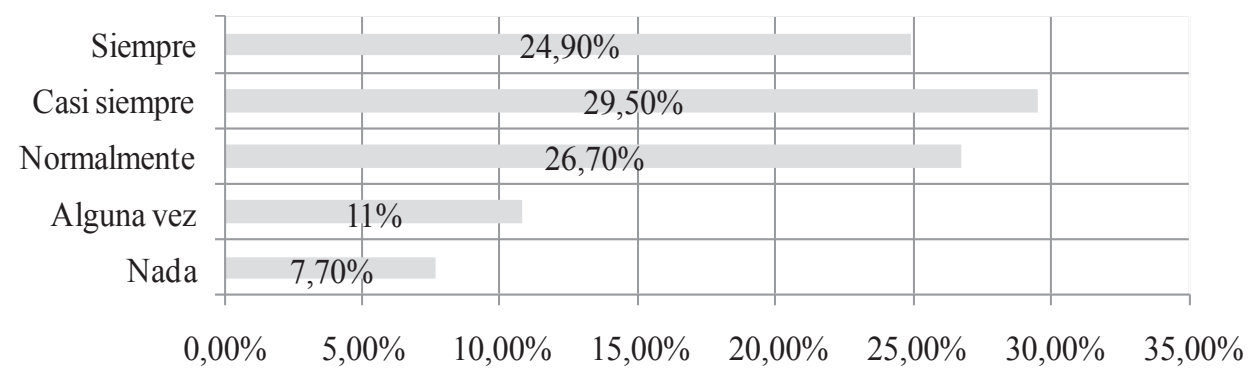

Fuente: elaboración propia.

En la pregunta cuarta, se interroga al encuestado sobre la utilización de los sitios web de viajes para comprar. Las encuestas válidas han sido 544, y se han excluido 2 encuestas de un total de 546. La media de esta variable ha sido de 3,53 lo que indica que la mayoría de los usuarios de los sitios web de viajes los utiliza casi siempre para comprar. En este caso, la desviación típica ha sido de 1,197 y expresa la heterogeneidad de la variable. En la figura 7, se visualiza que el 29,50\% (161 de los 546 usuarios) utiliza los sitios web de viajes casi siempre; es el resultado más significativo. El resto de resultados de esta variable que detallamos a continuación son los siguientes: el 7,70\% (42 de los 546 usuarios) nunca ha utilizado un sitio web de viajes para comprar; el 10,8\% (59 de los 546 usuarios) los utiliza alguna vez; el 26,70\% (146 de los 576 usuarios) los utiliza normalmente; y, por último, el 24,90\% (42 de los 546 usuarios) los utiliza siempre.

En la pregunta quinta, se le interroga al encuestado para saber si utiliza los sitios web de viajes para dar una opinión. Las encuestas válidas han sido 542, y 4 fueron excluidas de un total de 546. La media de esta variable ha sido de 1,50 e indica que los sitios web de viajes se utilizan alguna vez para dar una opinión. En este caso, la desviación típica ha sido de 0,870 , dada la heterogeneidad de la variable, aunque menos que la anterior. En la figura 8, se observa que el 67,90\% (371 de los 546 usuarios) nunca utiliza los sitios web de viajes para dar una opinión, por lo que consideramos este resultado como el más 
relevante. El resto de resultados de esta variable se detalla a continuación: el 18\% (100 de los 546 usuarios) los ha utilizado alguna vez; el 8,10\% (44 de los 546 usuarios) los utiliza normalmente; el 4,20\% (23 de los 576 usuarios) los utiliza casi siempre; y, por último, el $0,7 \%$ (4 de los 546 usuarios) los utiliza siempre.

\section{Figura 8}

\section{CALIFIQUE LOS PRINCIPALES MOTIVOS POR LOS QUE UTILIZA LOS SITIOS WEB DE VIAJES (DAR UNA OPINIÓN)}

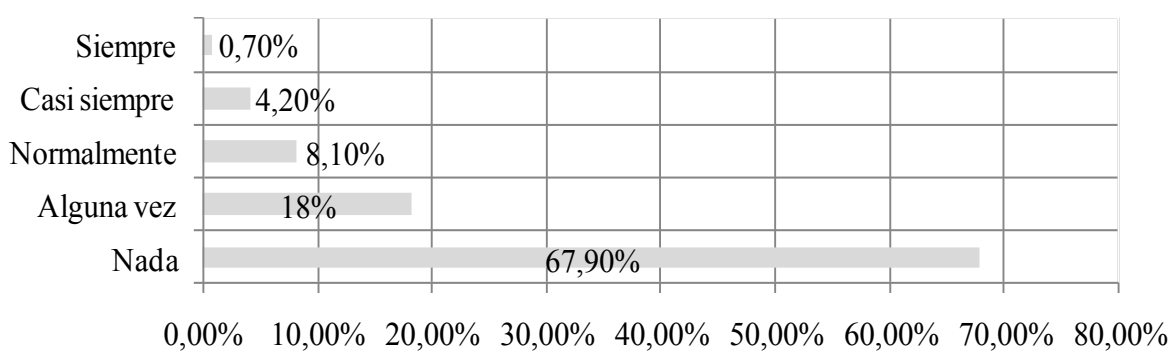

Fuente: elaboración propia.

En la sexta, se le pregunta al encuestado para saber si utiliza los sitios web de viajes para ver imágenes. Las encuestas válidas han sido 540, y 6 han sido excluidas de un total de 546. La media de esta variable ha sido del 3,45, lo que indica que los sitios web de viajes se utilizan casi siempre para ver imágenes. En este caso, la desviación típica ha sido de 1,276 por lo que esta variable es considerada muy heterogénea, ya que los resultados son muy dispersos. En la figura 9, podemos ver que el 29,90\% (163 de los 546 usuarios) casi siempre utiliza los sitios web de viajes para ver imágenes, y es este resultado el más significativo. El resto de resultados de esta variable son los siguientes: el 13,6\% (74 de los 546 usuarios) los ha utilizado alguna vez para ello; el 21,1\% (115 de los 546 usuarios) los utiliza normalmente; el 10,1\% (55 de los 576 usuarios) nunca los utiliza; y, por último, el $24,4 \%$ (133 de los 546 usuarios) los utiliza siempre.

\section{Figura 9}

\section{CALIFIQUE LOS PRINCIPALES MOTIVOS POR LOS QUE UTILIZA LOS SITIOS WEB DE VIAJES (VER IMÁGENES)}

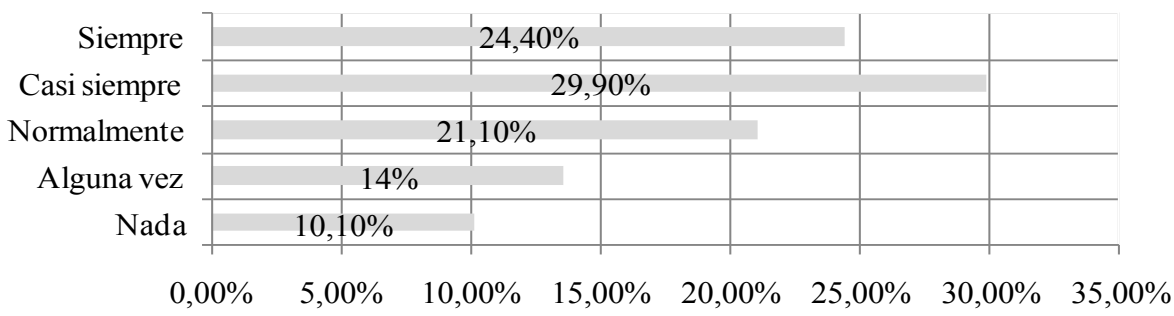

Fuente: elaboración propia. 
En la pregunta séptima, se interroga al encuestado para saber si utiliza los sitios web de viajes para visionar vídeos. Las encuestas válidas han sido 540 y 6 no válidas de un total de 546. La media de esta variable ha sido de 2,63 lo que indica que los sitios web de viajes se utilizan normalmente para ver vídeos. En este caso, la desviación típica ha sido de 1,334 por lo que la variable es mucho más heterogénea que la variable anterior de visionar imágenes. La figura 10 prueba que el 26,2\% (143 de los 546 usuarios) nunca utiliza los sitios web de viajes para visionar vídeos; es el resultado más relevante. Los demás resultados de esta variable fueron los siguientes: el 23,1\% (126 de los 546 usuarios) los ha utilizado alguna vez; el 21,8\% (119 de los 546 usuarios) los utiliza normalmente; el 16,1\% (91 de los 576 usuarios) los utiliza casi siempre; y, por último, el 11,2\% (61 de los 546 usuarios) los utiliza siempre para ver vídeos.

\section{Figura 10}

\section{CALIFIQUE LOS PRINCIPALES MOTIVOS POR LOS QUE UTILIZA LOS SITIOS WEB DE VIAJES (VER VÍDEOS)}

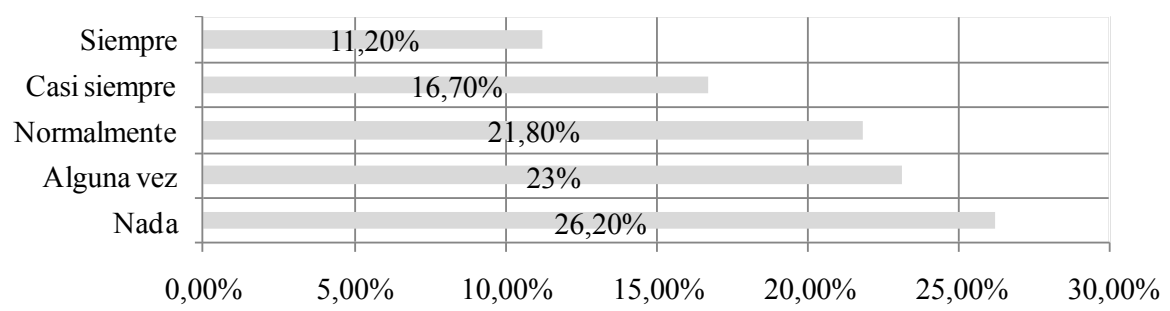

Fuente: elaboración propia.

En la octava, se pregunta al encuestado si utiliza los sitios web de viajes para leer comentarios. Las encuestas válidas han sido 541 de un total de 546, y se dieron 5 encuestas como perdidas. La media de esta variable ha sido de 3,51, lo que nos indica que los sitios web de viajes se utilizan casi siempre para leer comentarios. En este caso, la desviación típica ha sido de 1,269 y es indicativa de la heterogeneidad de dicha variable.

Figura 11

CALIFIQUE LOS PRINCIPALES MOTIVOS POR LOS QUE UTILIZA LOS SITIOS WEB DE VIAJES (LEER COMENTARIOS)

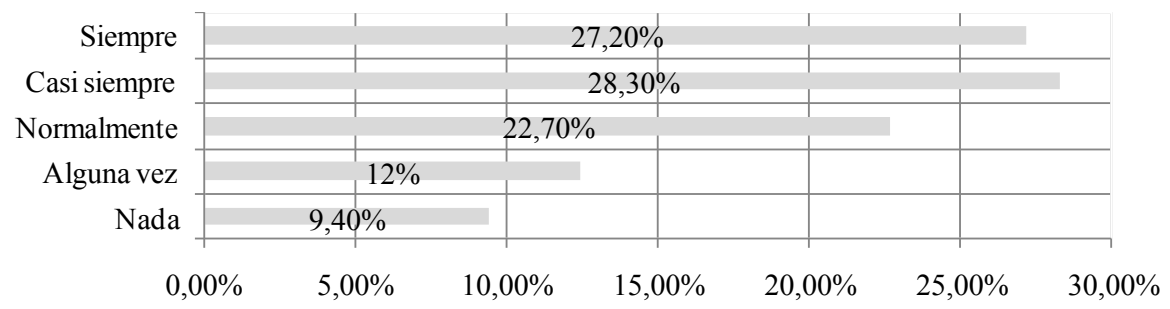

Fuente: elaboración propia. 
La figura 11 muestra que el 28,3\% (153 de las 541 encuestas válidas) casi siempre utiliza los sitios web de viajes para leer comentarios; este es el resultado más significativo. El resto de resultados de esta variable, que se detalla a continuación, fue: el 12,4\% (67 de las 541 encuestas válidas) los ha utilizado alguna vez; el 22,7\% (123 de las 541 encuestas válidas) los utiliza normalmente; el 27,2\% (147 de las 541 encuestas válidas) los utiliza casi siempre; y, por último, el 9,4\% (51 de las 541 encuestas válidas) nunca los utiliza.

En la pregunta novena, se interroga al encuestado para saber si utiliza los sitios web de viajes para comparar precios. Las encuestas válidas han sido 545 de un total de 546, y se dio una encuesta como perdida. La media de esta variable ha sido de 4,42 e indica que los sitios web de viajes se utilizan siempre para comparar precios. En este caso, la desviación típica ha sido de 0,861 y es indicativa de una mayor homogeneidad en torno a la utilización de los sitios web de viajes para comparar precios. En la figura 12, podemos apreciar que el 59,80\% (326 de las 545 encuestas válidas) utiliza siempre los sitios web de viajes para comparar precios, por lo que es el resultado más relevante. El resto de resultados de esta variable se detalla a continuación: el 2,8\% (15 de las 545 encuestas válidas) los ha utilizado alguna vez; el 7,7\% (42 de las 545 encuestas válidas) los utiliza normalmente; el 28,3 (154 de las 545 encuestas válidas) casi siempre los utiliza; y, por último, el 1,5\% (8 de las 545 encuestas válidas) nunca los utiliza.

Figura 12

\section{CALIFIQUE LOS PRINCIPALES MOTIVOS POR LOS QUE UTILIZA LOS SITIOS WEB DE VIAJES (COMPARAR PRECIOS)}

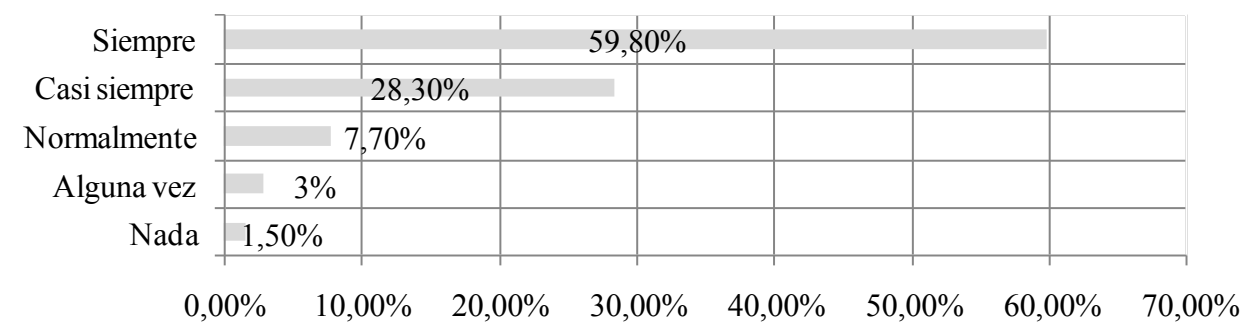

Fuente: elaboración propia.

En la pregunta décima, se interroga al encuestado para saber si utiliza los sitios web de viajes para buscar información. Las encuestas válidas han sido 544 de un total de 546, y se dieron 2 encuestas como perdidas.

La media de esta variable ha sido de 4,33 lo que indica que los sitios web de viajes se utilizan siempre para buscar información y comparar. En este caso, la desviación típica ha sido de 0,900 e indica una mayor homogeneidad en torno a la utilización de los sitios web de viajes para buscar información. En la figura 13, podemos visualizar que el 53,10\% (289 de las 544 encuestas válidas) de los usuarios utiliza siempre los sitios web de viajes para buscar información, y este resultado es el más significativo. Los demás resultados de esta variable, que se detallan a continuación, son los siguientes: el 2,4\% (13 de las 544 
encuestas válidas) los ha utilizado alguna vez; el 9\% (49 de las 544 encuestas válidas) los utiliza normalmente; el 33\% (181 de las 544 encuestas válidas) casi siempre los utiliza; y, por último, el 2,2\% (12 de las 544 encuestas válidas) nunca los utiliza.

\section{Figura 13}

\section{CALIFIQUE LOS PRINCIPALES MOTIVOS POR LOS QUE UTILIZA LOS SITIOS WEB DE VIAJES (BUSCAR INFORMACIÓN)}

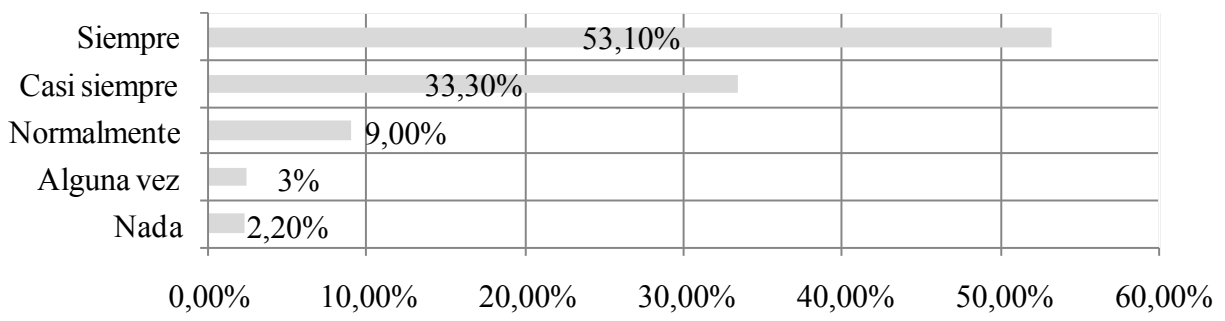

Fuente: elaboración propia.

En la pregunta undécima, que está compuesta por una única variable, se le pide al encuestado que indique el sitio web de viajes que más suele utilizar. Para ello, se le facilitó una ficha técnica dividida entre los diferentes tipos de sitios web de viajes (proveedores de servicios «online», sitios web de viajes de opinión, motores de búsqueda, sitios web de destinos y agencias de viajes «online») y con numerosos ejemplos de cada tipo de sitio web (ej. «Motores de búsqueda»*«Trivago»). En la encuesta, solo se le pedía el nombre del sitio web para después poder clasificarlo internamente según el cuadro de códigos de este cuestionario.

Como se puede visualizar en la figura 14, las encuestas válidas han sido 546 de un total de 546. En este caso, la desviación típica ha sido de 1,859, lo que indica una gran heterogeneidad en el uso de los diferentes tipos de sitios web de viajes. En la figura 14, podemos visualizar que el 41\% (224 de las 546 encuestas válidas) utiliza las agencias de viajes «online», por lo que es este resultado el más significativo. El 0,7\% (4 de las 546 encuestas válidas) utiliza los sitios web de destinos; el 21,1\% (115 de las 546 encuestas válidas), los sitios web de motores de búsqueda; el 18,5\% (101 de las 546 encuestas válidas), los sitios web de viajes de opinión; el 1,1\% (6 de las 546 encuestas válidas), los sitios web de proveedores de servicios de alojamientos (hoteles, moteles, hostales, casas rurales, etc.); y, por último, el 17,6\% (96 de las 546 encuestas válidas) utiliza los sitios web de proveedores de servicios de transporte (aéreo, marítimo y terrestre).

Además de clasificar los diferentes sitios web de viajes según la tipología de la distribución, hemos querido clasificar internamente los diferentes sitios web de viajes que más se utilizan por los usuarios, puesto que nos parece un dato relevante y de suma importancia para la investigación. Como pueden observar, el cuadro 3 está dividido en proveedores de servicios «online» (transportes), proveedores de servicios «online» (alojamiento), sitios web de viajes de opinión, motores de búsqueda «online», sitios web de destinos turísticos y agencias de viajes «online» (mayoristas y minoristas). 


\section{Figura 14 \\ INDIQUE EL SITIO WEB DE VIAJES QUE MÁS SUELE UTILIZAR}

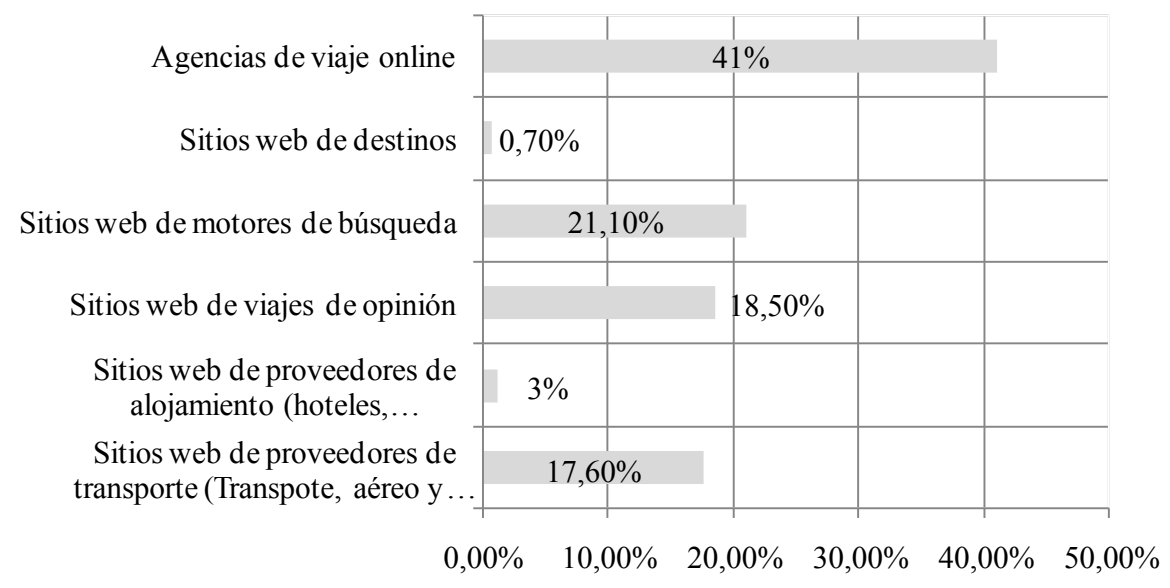

Fuente: elaboración propia.

Dentro de las agencias de viajes «online» que, como mencionamos en la figura 14, representan el $41 \%$ del total de los sitios web de viajes más utilizados, podemos afirmar que en nuestra investigación se han nombrado 13 sitios web de agencias de viaje distintas (Atrápalo; Booking; Edreams; Easyjet; Logitravel; Rumbo; Lastminute; Muchoviaje.com; Expedia; Halcon viajes; Niumba; Viajes Ecuador y Voyage privé), y que, por encima de todas, destacan tres (Booking, Edreams y Rumbo), de las cuales la más mencionada por 76 usuarios fue Booking.

Entre los proveedores de servicios (transporte) que, como visualizamos en la figura 14, representan el 17,6\% del total de los sitios web de viajes más utilizados, podemos afirmar que en nuestra investigación se han nombrado 13 proveedores de servicios «online» (transporte) distintos (Aireuropa; Ryanair; British Airways; Lufhansa; Vueling; Renfe; Iberia; Rentalia; Avanzabus; Alsa; Airfrance; Royalcaribbean); que, por encima de todos, destacan tres (Ryanair, Renfe e Iberia); y que Ryanair, la más mencionada, lo fue por 39 usuarios. Entre los proveedores de servicio (alojamientos), que representan solo un $3 \%$ del total, la única que ha sido mencionada por 5 usuarios es NH Hoteles.

Entre los sitios web de opinión, que representan el 18,5\% del total de sitios web más utilizados, podemos afirmar que en la muestra se han nombrado 7 (Minube; Ruralka; Escapadarural; Toprural; Lonely Planet; Turisteye; Tripadvisor) de sitios web de viajes de opinión, y que Tripadvisor es el más utilizado de toda la muestra de investigación (85 usuarios)

De los motores de búsqueda «online», que representan el $21 \%$ del total de los sitios web más utilizados y nombrados en la muestra, destacan 3 sitios web (Skyscanner, Trivago y Kayak), y el más utilizado fue Trivago (66 usuarios). Entre los sitios web de destinos, que representan el $0,7 \%$ del total de sitios web de viajes, podemos afirmar que en nuestro trabajo se han mencionado 2 dos sitios web (Esmadrid y Tourspain) sin ninguna relevancia. 


\section{Cuadro 3 \\ SITIOS WEB DE VIAJES QUE MÁS UTILIZAN LOS USUARIOS}

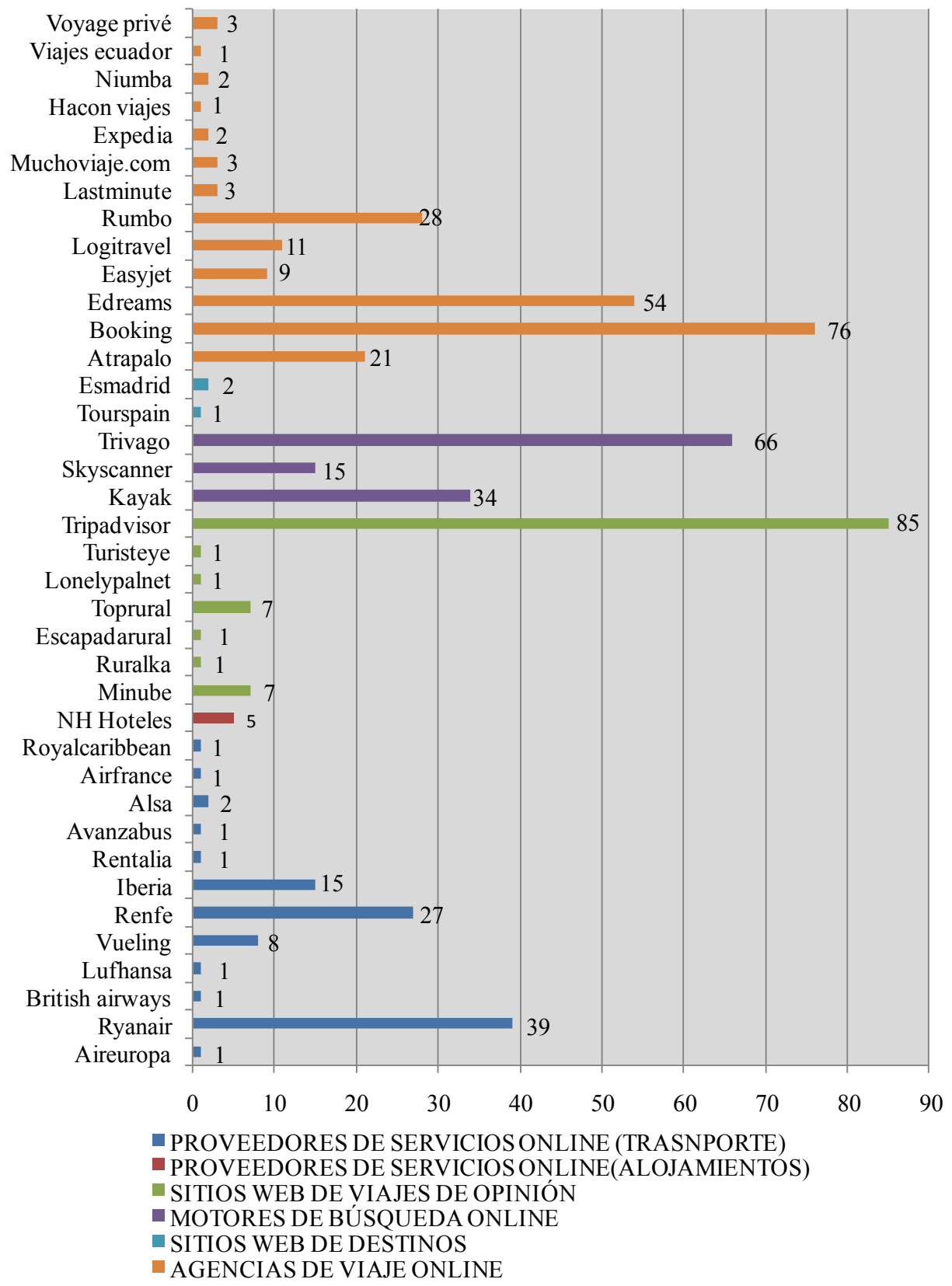

Fuente: elaboración propia. 


\section{CONCLUSIONES}

En este apartado, recogemos las conclusiones en el mismo orden de las preguntas. En efecto, las contribuciones empíricas más importantes a la praxis académica han sido las siguientes:

Respondiendo al primer objetivo planteado al principio de nuestra de investigación, podemos afirmar que la estructura del sistema de distribución de servicios turísticos «online» ha cambiado drásticamente con la irrupción de nuevos intermediarios (sitios web de opinión, sitios web de motores de búsqueda y sitios web de destino), debido a la aparición de los Medios Sociales. En cuanto al segundo objetivo, podemos afirmar que el 40,07\% de los usuarios encuestados recurre a estos nuevos intermediarios en vez de recurrir a los tradicionales para la planificación de sus viajes.

Respecto de los resultados de esta investigación, podemos afirmar que el 52,3\% de los usuarios utiliza los sitios web varias veces al año y un $22 \%$ los usa varias veces al mes. Esto indica que la mayoría de los usuarios recurre a los sitios web de viajes solo cuando pretende realizar algún tipo de viaje. El 99,6\% de los usuarios que utilizan este sitio web de viajes lo hace para planificar su viaje. El 74,4\% de los usuarios no genera ningún tipo de contenido en los sitios web de viajes desde sus «smartphones». Este dato indica que la mayoría de los sitios web no desarrollan actividades de marketing móvil.

Se constata que el principal motivo de uso de los sitios web de viajes es comparar precios con un 59,8\% del total; el segundo motivo de uso de los sitios web de viajes es buscar información en general con un 53,10\% del total; el tercer motivo de uso de los sitios web es ver imágenes con un 29,90 del total; el cuarto motivo de uso de los sitios web de viajes es comprar con un $29,5 \%$ del total; y el quinto, y último motivo de uso de los sitios web de viajes, es leer comentarios con un $28,3 \%$ del total. Con estos resultados, queda constatado el cambio que están sufriendo los sitios web de viajes con la incorporación de los Medios Sociales. Antiguamente, los principales motivos de uso de los usuarios eran comprar y buscar información. Con esta investigación, hemos demostrado que actualmente estos motivos han cambiado radicalmente.

Aunque hemos encontrado datos muy reveladores, pues los sitios web de viajes que más se utilizan siguen siendo las agencias de viaje «online» con cerca de un $41 \%$ del total, merece la pena resaltar y analizar el aumento considerable de los sitios web de viajes identificados como motores de búsqueda y sitios web de opinión. Al contrastar estos datos con los anteriores y con los principales motivos de uso de los sitios web de viajes, podemos concluir que, si el principal motivo de uso es comparar precios, parece lógico pensar que los sitios web de motores de búsqueda sean utilizados por un $21,1 \%$ del total de los usuarios. Otro de los principales motivos de uso de los sitios web de viajes es ver imágenes y leer comentarios, por lo que entra dentro de lo lógico comprobar que el 18,5\% de los usuarios utiliza los sitios web de viajes de opinión. Los datos más sorprendentes han sido la constatación de la escasa utilización de los sitios web de viajes de hoteles, apartamentos y casas rurales con un $1,1 \%$ y los sitios web de destinos turísticos con un $0,7 \%$.

Otro objetivo era comprobar qué sitio web de viajes era el más utilizado. En este sentido, podemos afirmar que, de los sitios web de viajes de transportes, los más utilizados son el de Ryanair y Renfe. Dentro de los sitios web de viajes de alojamientos, NH hoteles es el más 
frecuentado. Dentro de los sitios web de viajes de opinión, el más utilizado es Tripadvisor, que también es el sitio web más utilizado de toda la encuesta. Dentro de los sitios web de viajes de motores de búsqueda, el más utilizado ha sido Trivago. Y, dentro de los sitios web de viajes de agencias de viaje, los más utilizados han sido Booking, Atrapalo, Rumbo y Edreams.

\section{BIBLIOGRAFÍA}

ALFARO, M. (2004): Temas clave del Marketing Relacional. Mc-Graw-Hill. Madrid.

BENNET, M. y LAI, K. (2005): «The Impact of the Internet on Travel Agencies in Taiwan». Tourism and Hospitality Research, vol. 6, $\mathrm{n}^{\circ}$ 1, pp. 8-23.

BERNÉ, C., GARCÍA, M., GARCÍA, E. y MÚGICA, M. (2011): «La influencia de las TIC en la estructura del sistema de distribución turístico». Cuadernos de Turismo, vol. 28, pp. 9-22.

BERNÉ, C., GARCÍA-GONZÁLEZ, M., GARCÍA-UCEDA, M.E. y MÚGICA, J. M. (2013): «Identificación y análisis de los criterios de cambios del sistema de distribución turístico asociados al uso intensivo de las tecnologías de la información y de la comunicación», Investigaciones Europeas de Dirección y Economía de la Empresa, vol. 19, n⿳2 2, pp. 90- 101.

BERNÉ, C., GARCÍA-GONZÁLEZ, M., GARCÍA-UCEDA, E. y MÚGICA, M. (2012): «Modelización de los cambios en el sistema de distribución del sector turístico debidos a la incorporación de las tecnologías». Cuadernos de Economía y Dirección de la Empresa, vol. 15, n 3, pp. 117-129.

BLOCH, M. (1996): Letter to Travel Agents. Disponible en http://haas.berkley.edu/ citm

BOYD, D.M. y ELLISON, N.B. (2008): «Social network sites: Definition, history and scholarship». Journal of Computer-Mediated Communication, vol. 13, pp. 210-230.

BUHALIS, D. (1998): «Strategic Use of Information Technologies in the Tourism Industry». Tourism Management, vol.19, nº 5, pp. 409-421.

BUHALIS, D. (2003): E-Tourism: Information Technology for Strategic Tourism Management. London, UK: Pearson.

BUHALIS, D. y LAW, R. (2008): «Progress in information technology and tourism management: 20 years on and 10 years after the Internet - The state of e-Tourism research». Tourism Management, vol. 29, nº 4, pp. 609-623.

BUHALIS, D. y LICATA, M. (2002): «The future of e-Tourism intermediaries». Tourism Management, vol. 23, pp. 207-220.

CONSTANTINIDES, E. y FOUNTAIN, S., (2007): «Web 2.0: Conceptual Foundations and Marketing Issues». Journal of Direct, Data and Digital Marketing, vol. 9, $\mathrm{n}^{\circ} 3$, pp. 231-244.

COOPER, C., FLETCHER, J., FYALL, A., GILBERT, D. y WANHILL, S. (2005): El turismo, teoría y práctica. Editorial Síntesis, Madrid.

COUGHLAN, A.T., ANDERSON, E., STERN, L.W. y EL-ANSARY, A.I. (2001): Marketing Channels (6th ed.). Upper Saddle River, NJ: Prentice Hall.

DOHERTY, N. F., ELLIS-CHADWICK, F. y HART, C. A. (1999): «Cyber Retailing in the UK: The Potential of the Internet as a Retail Channel». International Journal of Retail \& Distribution Management, vol. 27, $\mathrm{n}^{\circ}$ 1, pp. 22-36. 
EMMER, R., TAUCK, C., WILKINSON, S., y MOORE, R. (1993): «Marketing hotels using global distribution systems». The Cornell Hotel Restaurant Administration Quarterly, vol. 34, n 6, pp. 80-89.

FREW, A.J. (2000): «Information and Communications Technology Research in the Travel and Tourism Domain: Perspective and Direction». Journal of Travel Research, vol. 39, $\mathrm{n}^{\mathrm{o}} 2$, pp. 136-145.

GUMMESSON, E. (2002): Total Relationship Marketing, 2nd edition, Butterworth Heinemann, Oxford.

GUNASEKARAN, A., MARRI, H., MCGRAUGHEY, R. y NEBHWANI, M., (2002): «E-commerce its impact on operations management». International Journal of Production, vol. 75, pp. 185-197.

KALE, S. y MCINTYRE, R., (1991): «Distribution channel relationships in diverse cultures». International Marketing Review, vol. 8, nº 3, pp. 31-45.

KAPLAN, A.M. y HAENLEIN, M. (2009): «The fairyland of second life: About virtual social worlds and how to use them». Business Horizons, vol. 52, nº, pp. 563-572.

KASAVANA, M. y CAHILL, J., (1992): Managing Computers in the Hospitality Industry, edition. Educational Institute of the American Hotel and Motel Association, Lansing, Michigan

LANDETA, J. (1999): El método Delphi. Ariel, Barcelona.

LEUNG, R. y LAW, R. (2007): «Analyzing Research Collaborations of Information Technology Publications», Leading Hospitality and Tourism Journals: 1986-2005. In: Sigala, M. Minch, M. and Murphy, J. (eds.) Information and Communication Technologies in Tourism. Wien, pp. 547-557.

LUSCH, R.F. y VARGO, S.L. (2006): «Marketing as service-exchange: Taking a leadership role in global Marketing management». Organizational Dynamics, vol. 35, $\mathrm{n}^{\circ} 3$, pp. 264-278.

NIELSEN (2011): The Social Media Report -3rd Quarter 2011. Nielsen/McKinsey Company, Nueva York (Estados Unidos).

NOVAK, J. Y SCHWABE, G. (2009): «Designing for reintermediation in the brick-andmortar world: Towards the travel agency of the future». Electronic Markets, vol. 19, $\mathrm{n}^{\mathrm{o}} 1$, pp. 15-29.

O'CONNOR, P. (2003): «Room Rates on the Internet-is the Web Really Cheaper?» Journal of Services Research, vol. 1, $\mathrm{n}^{\circ} 1$, pp. 57-72.

O'REILLY, T. (2005): What is Web 2.0? Disponible en http://www.oreillynet.com/pub/a/ oreilly/tim/news/2005/09/30/what-is-web-20.html

POON, A. (1993): Tourism, Technology and Competitive Strategies. CAB International. 2003.

PORTER, M.E. (1990): «The Competitive Advantage of Nations», Harvard Business Review, Macmillan and Co., London, vol. 69, pp. 73-91.

RENSMANN, B. (2012): «Towards a typology of retail Cybermediation in Tourism Markets». Information and Communication Technologies in Tourism, pp. 344-355.

RODRÍGUEZ, I. (2002): Marketing.com y comercio electrónico en la sociedad de la información. Pirámide, Madrid. 
ROSSELLÓ, J. y AGUILÓ, E y RIERA, A. (2005): «Modeling Tourism Demand Dynamics». Journal of Travel Research, vol. 44, $\mathrm{n}^{\circ}$ 1, pp. 111-116.

SALONER, G. y SPENCE, A. (2002): Creating and capturing value: Perspectives and cases on electronic commerce. New York: Wiley \& Sons.

SANCHO, A. (Coord.) (1998): Introducción al Turismo, Organización Mundial del Turismo (OMT), Madrid.

SARMIENTO, J.R. (2014): El Marketing de Relaciones en los medios sociales: estudio empírico de los antecedentes y consecuentes de la calidad de la relación en los sitios web de viajes. Tesis doctoral. Universidad Rey Juan Carlos. Madrid.

SELLERS, R. y AZORÍN, A. (2001): «El comercio electrónico y el futuro del canal de distribución turístico». Investigaciones Europeas de Dirección y Economía de la Empresa, vol. 7, n 1, pp. 13-36.

SHELDON, P. (1993): «Destination information systems». Annals of Tourism Research, vol. 20, no 4, pp. 633-649.

SHELDON, P.J. (1997): Information Technologies for Tourism. CAB, Oxford.

SUROWIECKI, J. (2004): The Wisdom of Crowds. New York, NY: W. W. Norton \& Company, Inc.

TAPSCOTT, D. (2009): Grown up digital: how the net generation is changing your world. New York: McGraw-Hill.

TIWANA, A. (1998): «Interdependency factors influencing the World Wide Web as a channel of interactive marketing». Journal of Retailing and Consumer Services, vol. $5, n^{\circ} 4$, pp. 245-253.

TOFFLER, A. (1984): Future shock. Bantam.

VALLESPÍN, M. y MOLINILLO, S. (2014): «El futuro de la intermediación en el sector turístico». Revista de Análisis Turístico, vol. 17, n 1, pp. 13-25.

VARGO, S. y LUSCH, R. (2004): «Evolving to a Dominant Logic for Marketing». Journal of Marketing, vol. 68, $\mathrm{n}^{\mathrm{O}} 1$, pp. 1-17.

WANG, Y.S., WANG, Y.M., LIN, H.H., y TANG, T.I. (2003): «Determinants of user acceptance of internet banking: an empirical study». International Journal of Service Industry Management, vol. 14, nº 5, pp. 501-19. 
